\title{
Prevalence and Microbiological Profile of Catheter Associated Urinary Tract Infections: A Survey in Secondary Care Hospital in Gaza Strip
}

\author{
Aymen Elsous ${ }^{1,2^{*}}$, Mahmoud Ouda², Samah Mohsen², Mohammed Al-Shaikh², \\ Siham Mokayad ${ }^{2}$ \\ ${ }^{1}$ Department of Health Management and Economics, School of Public Health, International Campus, Tehran \\ University of Medical Sciences, Tehran, Iran. ${ }^{2}$ Quality Improvement and Infection Control Office, Shifa Medical \\ Complex, Ministry of Health, Gaza Strip, Palestine.
}

First Published online June 30, 2016

\begin{abstract}
Background and Objectives: Healthcare-associated infections is a major health care concern posing potentially serious negative impact on patient safety and outcome. In this paper, we report this microbiological profile and the prevalence of catheter associated urinary tract infections (CAUTIs).

Methods: This was a prospective observational study for 60 inpatients from 8 wards among patients having indwelling catheter for at least 48 hours. Urine cultures were taken in initial phase within 24 hours of admission, at 48 hours and in day 5 of catheterization.

Findings: The rate of CAUTIs was $16.7 \%$ after 48 hours and $28 \%(7 / 25)$ after 5 days from insertion the indwelling catheter. Candida spp. was the most common cause of CAUTIs (29.4\%), followed by Escherichia coli (23.5\%), Streptococcus spp. and Klebsiella spp. (17.6\%) and last Staphylococcus spp. (11.7\%). The coronary care unit (CCU) showed the highest prevalence of CAUTIs (57.1\%), followed by Oncology (42.8\%), and Internal Medicine (33.3\%). Females showed a significantly higher rate of acquired urinary tract infections (UTIs) compared with males $(P<.05)$.

Conclusions: The risk of CAUTIs was found to be relatively high and increase by duration of catheterization. These results recommend minimally usage of catheter in medical practice in terms of both frequency and time, particularly for female patients and in CCU ward. Identification of the microbiological profile of the CAUTIs would help efficient treatment of the infected patients.
\end{abstract}

Keywords: Catheter associated urinary tract infections, Prevalence, Hospital, Microbiological profile

\section{Background and Objectives}

People who seek healthcare are unable to tolerate the additional burden of acquiring a new infection. Healthcare associated infections (HAls) are a major concern for healthcare management and frontlines to maximize patient safety. HAI is global health problem because of their seriousness, burden and costs to healthcare system. They also impose serious problems to safety of t patients. ${ }^{1}$ In developing countries, the prevalence and incidence of HAls varies between 5.7 to 19.1 , and 1.7 to 23.6 per 100 patients respectively. ${ }^{2}$ Studies from European hospitals

${ }^{*}$ Corresponding Author: Aymen Mohammed Elsous, Quality Improvement and Infection Control Office, Shifa medical complex, Ministry of Health, Gaza Strip, Palestine. Tel: +970598926886,

Email: aymenelsous65@gmail.com indicates that 1 in every 18 patients has HAls. ${ }^{3}$ In the United States 1.7 million suffer from HAls and 100000 dies every year as result of these infections. ${ }^{4}$

Urinary catheterization occurs in $15 \%-25 \%$ of all hospitalized patients and urinary tract infections (UTIs) caused by urinary catheter are the most common type of HAls, ${ }^{5}$ representing $30 \%$ to $40 \%$ of all HAls in some regions of the world. ${ }^{6-9}$ Over $80 \%$ of catheter associated urinary tract infections (CAUTIs) are linked to insertion of indwelling catheter. ${ }^{10}$ The rate of these infections can be reduced through effective infection prevention and control program (ICP). ${ }^{3,11}$ It is estimated that strict infection and prevention program in has resulted in 15\%-69\% reception in infection and prevention of 9000 deaths from CAUTIs. ${ }^{12,13}$

In Palestine, where ICP is at the beginning and starting 
to evolve, no precise or even estimated data are available on HAls. Having knowledge and accurate data on HAls will enable hospitals to develop their strategies and preventive measures to reduce the incidence and complications of HAls including CAUTIs. The aim of this study was (1) to determine the prevalence rate of CAUTIs, (2) to determine the profile of causative pathogens and (3) risk factors associated with CAUTIs.

\section{Methods}

\section{Study Design and Setting}

This prospective study was carried out in Shifa medica complex which situated in Gaza Strip, Palestine. This complex is the oldest and largest healthcare setting with 535 beds and includes 3 hospitals: surgical, internal medicine, and Gyn/Obst hospitals. Samples were taken from patients of five wards which were selected purposefully based on the frequency of catheter insertion, including internal medicine, intensive care unit (ICU), cardiac, burns and orthopedics wards.

\section{Data Collection and Sampling}

Data on patients' age, sex, disease, and type and place of catheterization, and hospitalization ward were obtained from patient's medical records. Patients who used condoms, supra-pubic catheter, and percutaneous nephrostomy tube and those who used catheter prior to admission to the selected wards were excluded. The plan was to take 3 urine samples from each patient: first, within 12 hours after insertion; second, 48 hours from admission, and third, in day 5 of admission. The urine samples were taken from the bifurcation of Foley's catheter with aseptic technique and put in a sterile container. The samples were immediately taken to microbiology lab for culture preparation.

\section{Culturing and Identification of Microorganism}

A plate with agar was used for culturing the urine sample and results were read after 24 hours incubation in ovum at $37^{\circ} \mathrm{C}$. Identification of microorganisms was carried out principally based on their morphology. However, in case of difficulty in identification, analytical profile index (API) technique was used to identify the microorganisms. A loop of 1 micron or 10 microns was used to pick up a drop of urine. The sample was then inoculated into blood agar media. Using the same loop, a second drop of urine was taken and then was inoculated into MacConkey agar media. Both plates were incubated for 24 hours at $37^{\circ} \mathrm{C}$. Gram (+) bacteria and Candida spp. were identified based on wet mount approach according to which 1 colony with 1 drop of normal saline is placed on slide for direct microscopic examination. Gram (-) bacteria were identified using API
20E (Analytical profile index for enterobacteriasea 20 test) ID Kit (bioMérieux, France).

\section{Case Definition}

According to the Centers for Disease Control and Prevention (CDC) definition, ${ }^{14}$ CAUTI is defined as: "A UTI where an indwelling urinary catheter was in place for $>2$ calendar days on the date of event, with the day of device placement being day 1 , and an indwelling urinary catheter was in place on the date of event or the day before. If an indwelling urinary catheter was in place for $>2$ calendar days and then removed, the UTI criteria must be fully met on the day of discontinuation or the next day."

\section{Statistical Analysis}

Data were analyzed using descriptive statistical methods. SPSS version 20 package was used for data analysis.

\section{Ethical Consideration}

The institutional review board of Shifa medical complex approved the study protocol in accordance with Helsinki Declaration. All patients or their families were briefed about the study purpose and their consent was obtained.

\section{Results}

\section{Characteristics of the Patients}

A total of 128 patients were enrolled from which 213 urine cultures were obtained and analyzed. After initial analysis of samples, samples from 68 patients were excluded because the first urine cultures were positive (asymptomatic bacteriuria) or the patient was discharged before taking the second urine sample. Table 1 presents the characteristics of participants. Of the total enrolled patients, $60 \%$ were female and $40 \%$ were male. The mean age was 52.8 \pm 19.50 years. A majority of cases (41.7\%) were hospitalized in ICU and most catheters insertion was taken place in the emergency department $(71.7 \%)$.

\section{Prevalence of CAUTIs}

The overall prevalence of CAUTIs was $28.3 \%$ (17/60). The prevalence was $16.7 \%(10 / 60)$ and $28 \%(7 / 25)$ after 48 hours and 5 days of insertion the indwelling catheter, respectively (Table 2). The coronary care unit (CCU) showed the highest prevalence of CAUTIs (57.1\%), followed by internal medicine (oncology) (42.8\%), and internal medicine $(33.3 \%)$ wards.

\section{Place of CAUTIS}

Table 3 shows the distribution of isolated microorganisms based on hospital wards and departments. While $71.6 \%$ $(43 / 60)$ of catheters were inserted in the department of 
Table 1. Patients' Characteristics

\begin{tabular}{lccc} 
Variables & $\begin{array}{c}\text { Total } \\
(\mathbf{n = 6 0})\end{array}$ & $\begin{array}{c}\text { Male } \\
(\mathbf{n = 2 4 )}\end{array}$ & $\begin{array}{c}\text { Female } \\
(\mathbf{n}=\mathbf{3 6})\end{array}$ \\
\hline Age (median \pm SD) & & & \\
$\leq 35$ years & $20.0 \pm 3.89$ & $22.0 \pm 3.34$ & $15.0 \pm 1.16$ \\
$36-60$ yeras & $55.0 \pm 6.87$ & $53.0 \pm 7.01$ & $57.5 \pm 6.46$ \\
$>60$ years & $71.0 \pm 7.78$ & $78.0 \pm 8.35$ & $70.5 \pm 7.52$ \\
\hline Gender $(\%)$ & & & \\
Male & 40 & & \\
Female & 60 & & \\
Ward specialty, $\mathrm{n}(\%)$ & & & \\
ICU & $25(41.7)$ & $16(66.7)$ & $9(25.0)$ \\
Cardiac & $7(11.7)$ & $4(16.7)$ & $3(8.3)$ \\
Orthopedic & $10(16.7)$ & $1(1.7)$ & $9(15)$ \\
Internal medicine & $18(30)$ & $3(5)$ & $15(25)$ \\
\hline $\begin{array}{l}\text { Place of insertion } \\
\text { Emergency }\end{array}$ & $16(71.7)$ & $7(29.2)$ & $9(25.0)$ \\
Department & $43(26.7)$ & $17(70.8)$ & $26(72.2)$ \\
$\quad$ Theatre & $1(1.7)$ & $0(0.0)$ & $1(2.8)$ \\
\hline
\end{tabular}

Abbreviation: SD, standard deviation.

Table 2. Distribution of Causative Agents

\begin{tabular}{lccccc}
\hline \multirow{2}{*}{ Organisms } & $\begin{array}{c}\text { Over all } \\
(\mathbf{n = 6 0 )}\end{array}$ & \multicolumn{2}{c}{$\begin{array}{c}\mathbf{4 8} \text { hours } \\
(\mathbf{n = 6 0 )}\end{array}$} & \multicolumn{2}{c}{$\begin{array}{c}\text { Day 5 } \\
(\mathbf{n = 2 5})\end{array}$} \\
\cline { 2 - 7 } & $\%$ & $\mathbf{n}$ & $\mathbf{6}$ & $\mathbf{n}$ & $\%$ \\
\hline Staphylococcus spp. & 11.7 & 1 & 10 & 1 & 14.3 \\
Streptococcus spp. & 17.6 & 2 & 20 & 1 & 14.3 \\
E. coli & 23.5 & 2 & 20 & 2 & 28.5 \\
Klebsiella spp. & 17.6 & 3 & 30 & 0 & - \\
Candida spp. & 29. & 2 & 20 & 3 & 42.8
\end{tabular}

Table 3. Distribution of Microorganisms Based on Hospital Wards

\begin{tabular}{lcccc}
\hline \multirow{2}{*}{ Hospital Wards } & \multicolumn{2}{c}{$\begin{array}{c}\text { 48 hours } \\
\text { Day 5 }\end{array}$} \\
\cline { 2 - 5 } & $\mathbf{n}=\mathbf{6 0})$ & \multicolumn{2}{c}{$(\mathbf{n = 2 5 )}$} \\
\hline ICU & 3 & 5.0 & 1 & 4.0 \\
CCU & 3 & 5.0 & 1 & 4.0 \\
Male orthopedic & 0 & 0.0 & 0 & 0.0 \\
Female orthopedic & 2 & 3.3 & 1 & 4.0 \\
Male internal medicine & 0 & 0.0 & 1 & 4.0 \\
Female internal medicine & 0 & 0.0 & 1 & 4.0 \\
Internal medicine (oncology) & 2 & 3.3 & 2 & 8.0 \\
\hline
\end{tabular}

admission, $26.7 \%(16 / 60)$ were inserted in emergency department, and only 1 case was inserted in theatre. The prevalence of CAUTIs was higher in wards $(27.9 \%)$ compared with emergency department (23.5\%).

\section{Cause of CAUTIS}

Of all CAUTIs, 7 (41.1\%) were due to gram-negative bacteria, 5 (29.4\%) were due to Candida spp. and 5 (29.4\%) were due to gram-positive bacteria. The most frequently isolated causative agent was Candida spp. (29.4\%), followed by Escherichia coli (23.5\%), Klebsiella spp. and Streptococcus spp. (17.6\%), and Staphylococcus spp. (11.7\%).

\section{Discussion}

In this study, the overall rate of CAUTIs was $28.3 \%$. For comparison, the rate of CAUTIs has been reported to be $3.1 \%,{ }^{16} 10.6 \%-12.6 \%,{ }^{17}$ and $10.7 \%{ }^{18}$ from studies conducted in Egypt, Britain, and Turkey, respectively. Other studies report the risk of bacteriuria with catheterization to be $3 \%-10 \%$ which grows to $100 \%$ after 30 days. ${ }^{19,20}$

In this study, CAUTIs were found to be higher among females and long hospitalized patients with catheter, and in CCU which is consistent with previous studies. ${ }^{18,22-25}$ However, unlike the study of Mladenovi et al no difference in rate of CAUTIs was observed among patients of different age group. ${ }^{21}$

We identified Candida spp. as the most frequently occurring microbe in CAUTIs, followed by E. coli, Klebsiella spp, Streptococcus spp. and Staphylococcus spp. A previous study from Serbia reported Candida spp, Pseudomonas aeruginosa, and Klebsiella spp. as the most commonly observed organisms in CAUTIs. ${ }^{21}$ Another report from Singapore identified Candida spp. as most common cause of CAUTIs. ${ }^{26}$ Laupland et $\mathrm{al}^{27}$ showed $E$. coli and Candida spp. were dominant cause of CAUTIs followed by Enterococcus spp. and $P$. aeruginosa.

\section{Conclusions}

The risk of CAUTIs was found to be relatively high and increase by duration of catheterization. These results recommend minimally usage of catheter in medical practice in terms of both frequency and time, particularly for female patients and in CCU ward. Identification of the microbiological profile of the CAUTIs would help efficient treatment of the infected patients.

\section{Abbreviations}

(HAI): healthcare acquired infection; (CAUTI): catheter associated urinary tract infection; (CCU): coronary care unit; (ICP): infection control program; (UTI): urinary tract infection.

\section{Competing Interests}

The authors declare no competing interests.

\section{Authors' Contributions}

AME, MAO, SM, SM, MS jointly designed the study. AME, SM, MS, SM were involved in data collection and analysis. AME, MAO made the major contribution towards revision of the manuscript. All authors read and approved the final manuscript. 


\section{Acknowledgments}

The authors are grateful to managing board, head nurses, and the nursing staff of the Shifa hospital for providing facilitation for conduction of this study. We also thank the head of laboratory department of Shifa hospital, Mr. Kayed Ahmad and the staff of Microbiology Unit, Mr. Nahed Abd El-Latif, Mrs. Hala Abdo and Mr. Mahmoud Al Jaro for their kind support. We also appreciate Mr. Abd Al-Rahman Hamad for helping us in analysis of the data.

\section{References}

1. Umscheid CA, Mitchell MD, Doshi JA, Agarwal R, Williams K, Brennan PJ. Estimating the proportion of healthcare-associated infections that are reasonably preventable and the related mortality and costs. Infect Control Hosp Epidemiol. 2011;32(2):101-114. doi:10.1086/657912.

2. Allegranzi B, Nejad SB, Combescure C, et al. Burden of endemic health-care-associated infection in developing countries: systematic review and meta-analysis. Lancet 2011;377(9761):228-241. doi:10.1016/S01406736(10)61458-4

3. European Centre for Disease Prevention and Control (ECDC). Point prevalence survey of healthcare-associated infections and antimicrobial use in European acute care hospitals 2011-2012. Stockholm: ECDC; 2013.

4. Klompas M, Yokoe D. Automated surveillance of healthcare-associated infections. Clin Infect Dis. 2009;48(1):1268-1275.

5. Fakih MG, Shemes SP, Pena ME, et al. Urinary catheter in the emergency department; vey elderly women are at high risk for unnecessary utilization. Am J Infect Control. 2010;38(9):683.

6. Stamm WE. Catheter-associated urinary tract infections: epidemiology, pathogenesis and prevention. Am J Med. $1991 ; 91(3 B): 65 S-71 S$.

7. Plowman R, Graves N, Griffin M, et al. The socio-economic burden of hospital acquired infection. Euro Surveill. 2000;5(4):49-50.

8. Ward TT, Jones SR. Genitourinary tract infections. In: Reese RE, Betts RF, eds. A Practical Approach to Infectious Diseases. 4th ed. Boston: Little, Brown, and Company; 1996:472-518.

9. Vincent J, Bihari D, Suter $P$, et al. The prevalence of nos ocomial infections in intensive care units in Europe. Results of the European Prevalence of Infection in Intensive Care (EPIC) Study. JAMA. 1995;274(8):639-644.

10. Anderson DJ, Kirkland KB, Kaye KS, et al. Under resourced hospital infection control and prevention programs: Penny wise, pound foolish? Infect Control Hosp Epidemiol 2007;28(7):767-773. Doi:10.1086/518518
11. National Health and Medical Research Council. Australian Guidelines for the Prevention and Control of Infection in Healthcare. http://www.nhmrc.gov.au/_files_nhmrc/ publications/attachments/cd33_complete.pdf. Published 2010.

12. Smyth ETM, Mcllvenny G, Enstone JE, et al. Four Country Healthcare Associated Infection Prevalence Survey 2006: overview of the results. J Hosp Infect. 2008;69(3):230-248.

13. Umscheid C, Mitchell M, Agarwal R, et al. Mortality From Reasonably-Preventable Hospital Acquired Infections. A Preventable Epidemic. Washington, DC; 2008.

14. Catheter-Associated Urinary Tract Infection (CAUTI) Event. CDC website. http://www.cdc.gov/nhsn/PDFs/ pscManual/7pscCAUTIcurrent.pdf. Accessed January 2014.

15. Maki DG, Tambyah PA. Engineering out the risk for infection with urinary catheters. Emerg Infec Dis. $2001 ; 7(2): 342-347$.

16. El-Kholy A, Saied T, Gaber M, et al. Device-associated nosocomial infection rates in intensive care units at Cairo University hospitals: first step toward initiating surveillance programs in a resource-limited country. Am J Infect Control. 2012;40(6):e216-e220. doi:10.1016/j. ajic.2011.12.010

17. Pickard R, Lam T, MacLennan G, et al. Types of urethral catheter for reducing symptomatic urinary tract infections in hospitalized adults requiring short-term catheterization: multicenter randomized controlled trial and economic evaluation of antimicrobial- and antiseptic-impregnated urethral catheters (the CATHETER trial) Health Technol Assess. 2012;16(47):1-197.

18. Temiz E, Piskin N, Aydemir H, et al. Factors associated with catheter-associated urinary tract infections and the effects of other concomitant nosocomial infections in intensive care units. Scand J Infect Dis. 2012;44(5):344349. doi: 10.3109/00365548.2011.639031.

19. Saint S, Lipsky BA, Goold SD. Indwelling urinary catheters: a one-point restraint. Ann Intern Med. 2002;137(2):125-127.

20. Warren JW, Tenney JH, Hoopes JM, Muncie HL, Anthony WC. A prospective microbiologic study of bacteriuria in patients with chronic indwelling urethral catheters. J Infect Dis. 1982;146(6):719-723.

21. Mladenovi J, Veljovi M, Udovi I, et al. Catheter-associated urinary tract infection in a surgical intensive care unit. Vojnosanit Pregl. 2015;72(10):883-888.

22. van der Kooi TII, de Boer AS, Manniën J, et al. Incidence and risk factors of device-associated infections and associated mortality at the intensive care in the Dutch surveillance system. Intensive Care Med. 2007;33(2):271-278. 
23. Bochicchio GV, Joshi M, Shih D, Bochicchio K, Tracy K, Scalea TM. Reclassification of urinary tract infections in critically III trauma patients: a time-dependent analysis. Surg Infect. 2003;4(4):379-385.

24. Leone M, Albanèse J, Garnier F, et al. Risk factors of nosocomial catheter-associated urinary tract infection in a polyvalent intensive care unit. Intensive Care Med. 2003;29(6):929-932.

25. Foxman B. Epidemiology of urinary tract infections: Incidence, morbidity, and economic costs. Am J Med. 2002;113(Suppl 1A):5-13.

26. Tay MK, Lee JY, Wee IY, Oh HM. Evaluation of intensive care unit-acquired urinary tract infections in Singapore. Ann Acad Med Singap. 2010;39(6):460-465.

27. Laupland KB, Bagshaw SM, Gregson DB, Kirkpatrick AW, Ross T, Church DL. Intensive care unit-acquired urinary tract infections in a regional critical care system. Crit Care. 2005;9(2):R60-R65.

\section{Please cite this article as:}

Elsous A, Ouda M, Mohsen S, Al-Shaikh M, Mokayad S. Prevalence and microbiological profile of catheter associated urinary tract infections: a survey in secondary care hospital in Gaza Strip. Int J Hosp Res. 2016;5(2):69-73. doi:10.15171/ ijhr.2016.13. 